\title{
How Medical Practice Has Gone Wrong: Causes of the Lack-of-Reproducibility Crisis in Medical Research
}

\author{
Henry H. Bauer \\ Chemistry and Science Studies, Virginia Polytechnic Institute and State University, Virginia, USA.
}

\begin{abstract}
Modern medical practice has gone wrong by over-emphasizing drug-based treatment for chronic, constitutional conditions. The failure to distinguish between infectious and innate conditions was exacerbated by misinterpretation of quantitative measures, inappropriate statistical analysis, and inadequate regulation. The drug industry has become too influential as a result of these mis-steps and is a source of many conflicts of interest that are barriers to improving matters. This article summarizes some of the current problems facing medical practice and offers suggestions to address these problems.

Received: 17 September 2015; Accepted after revision: 13 October 2015; Published: 22 October 2015.

Author for correspondence: Henry H. Bauer, Dean Emeritus of Arts and Sciences, Professor Emeritus of Chemistry and Science Studies, Virginia Polytechnic Institute and State University, 207 Woods Edge Court, Blacksburg, VA 24060-4015, USA. E-mail: hhbauer@vt.edu; hhbauer@spamarrest.com

How to cite: Bauer HH. How Medical Practice Has Gone Wrong: Causes of the Lack-of-Reproducibility Crisis in Medical Research. Journal of Controversies in Biomedical Research 2015; 1(1):28-39.

Doi: http://dx.doi.org/10.15586/jcbmr.2015.8

Licence: This open access article is licenced under Creative Commons Attribution 4.0 International (CC BY 4.0). http://creativecommons.org/licenses/by/4.0/
\end{abstract}

\section{Introduction}

Finding solutions to problems requires identifying their causes. Without that, only symptoms are likely to be addressed, leaving the root causes to generate further problems. The lack-of-reproducibility crisis in biomedical research is one of the indications that modern medicine in the most advanced countries has gone wrong in recent decades, as described and documented in many books and articles (1). In addition to publication of those works, reactions to what has been going wrong include an initiative toward explicitly evidence-based medicine (2-4) and founding of the Journal of Controversies in Biomedical Research.

Medicine has gone wrong through the synergy over many decades of several developments, some intellectual and some commercial or practical. Most fundamental is the failure to distinguish, in principle and in treatment, between infectious and noninfectious, innate, constitutional conditions. Diseases caused from outside the affected individual are different in kind from undesired health conditions arising from internal, inherent physiological processes, and they should be addressed differently. 
That fundamental failure to distinguish between basically different types of conditions has been exacerbated by the well-intentioned urge to make medical practice more scientific (illustrating the old saw that the road to hell is paved with good intentions). It had seemed reasonable to seek objective and quantitative measures of ill health as guides to diagnosis as well as treatment, so a large range of tests has become routine: blood pressure (BP), blood sugar, cholesterol levels, PSA, etc., etc.

Those measures are symptoms, but they came to be identified as the causes of ailments or even as those conditions themselves. Labeling away-from-average levels of BP, blood sugar, cholesterol, etc., as "risk factors" is readily misinterpreted to mean that modifying them could modify actual risk. That postulates a causative relationship between the measured quantity and the undesired condition of which it is a symptom, when all that is known is that there exists a statistical correlation - and correlation never proves causation. That confusion of correlation with causation, and of symptom with disease, became even more explicit as these measures came to be also called "surrogate markers" or "biomarkers" of disease. First, high BP and high levels of cholesterol were taken on the basis of statistical correlations to be biomarkers of cardiovascular disease (CVD) as well as risk factors for CVD. That led to administering drugs to lower BP as though high BP were itself CVD or actually caused CVD. The misinterpretation did not become quickly evident because the success of treatment was judged by the effect on BP, not on the actually desired outcome which is a decreased morbidity and mortality from CVD, lesser incidence of heart attacks and strokes.

Things have also gone wrong in how clinical trials are carried out, and especially in how results are analyzed and interpreted. There are innumerable pitfalls in the designing and carrying out of clinical trials - biased sampling, inappropriate control groups, many more. But there is also an overarching misapplication of the statistical analyses that guide actual medical practice: namely, the criterion for "statistical significance" is quite weak, and it does not reflect how large a supposed benefit might be; nor is that hoped-for benefit systematically compared to the risks of "side" effects. The deficiencies in the statistics are demonstrable not only on first principles, their consequences have shown up in practice in the fact that, increasingly in recent decades, approved drugs have had to be withdrawn from the market (5) at shorter and shorter intervals (6) after the initial approval.

The presumption that non-infectious conditions can be properly treated in the same manner as infectious ones (by "magic bullet" drugs), the confusion of correlation with causation, and the flaws in statistical interpretation have led to a huge increase in consumption of prescription drugs, bringing an enormous expansion of the pharmaceutical industry ("Big Pharma"), which has become the most profitable of all industries (7-9). That has led to pervasive conflicts of interest which have corrupted research and emasculated regulation. Addressing the overall problem or any of its major symptoms will require efforts to deal with all of these causes. Unfortunately they are not entirely independent of one another, partly as a result of pervasive conflicts of interest, partly because Big Pharma will actively oppose anything that threatens to restrict even inappropriate or illegal prescribing of drugs.

\section{Infectious and non-infectious conditions}

When illness is caused by something invading a host, one may reasonably hope that it is possible to kill the invader without harming the host; perhaps one could find a substance (a "magic bullet") that exploits differences between the physiologies of invader and of host. That is not a reasonable hope with viruses since their chemistry is so much like that of animal cells, and the most effective guard against viruses is by vaccination. Against bacteria, various chemicals and particularly antibiotics have been very successful. Although none is fully lethal to the invader while completely harmless to the host, undesired "side" effects can be managed by keeping the duration of treatment very short, typically on the order of days or weeks. By contrast, chronic conditions not caused by invading entities require lifelong treatment. 
Inflammation, cancer, cardiovascular disease, and organ dysfunctions are not caused by identifiable invading entities. They arise because something has gone wrong in the body's physiology. That physiology is an excruciatingly complicated interconnected system of signals and feedbacks and reactions which under normal circumstances maintains an extraordinarily stable set of conditions. There is no a priori reason to imagine that normal stability could be regained after a system dysfunction by administering a single substance or even a few. Yet presentday treatment of chronic, non-infectious ailments is based on this unlikely premise. That approach is not only without a reasonable basis in theory, it is also hazardous in practice because the treatment of chronic ailments is not restricted to short periods as with infectious diseases, it is intended to be lifelong. "Side" effects may cumulate very harmfully when drugs are taken without interruption for long periods, as with BP-lowering medications or blood-sugar controllers or cholesterol-lowering drugs.

The scare quotes on "side" effects are intended to emphasize that chemicals do not know what we want them to do, they just exert their chemical effects. Current advertisements for prescription drugs typically list a whole host of really dangerous "side" effects, albeit either in very fine print in pamphlets or on television in cheery voices as the screen shows joyful doings of happily smiling people, overwhelming any effect of those grave warnings of "side" effects. TV ads for Symbicort for asthma, for example, illustrate its possible benefits through grandparents interacting happily and actively with grandchildren. The truth is that it promises only that it "may lead to better breathing" (NB "may"), while possible serious "side" effects include increased risk of hospitalization or death from asthma (the condition supposed to be treated), pneumonia, serious allergic reactions, decreased immune function, adrenal insufficiency, more wheezing, glaucoma, cataracts, lower bone density, swelling of blood vessels; as well as some common and "non-serious" "side" effects: "nose and throat irritation, headache, upper respiratory tract infection, sore throat, sinusitis, stomach discomfort, flu, back pain, nasal congestion, vomiting, and thrush in the mouth and throat" (10).

\section{Making medical practice objective}

Much has been learned by measuring a host of physiological variables. Nowadays blood tests report the levels of a great variety of substances, and measuring BP is routine at every visit to a doctor (despite the wellknown fact that BP rises owing to stress associated with having to consult a doctor). The devil is in the detailed ways in which BP and other measures are interpreted, and the treatments to which they lead more or less routinely. How things started to go wrong has been detailed by Greene (11). BP had been measured since early in the $20^{\text {th }}$ century. Insurance companies learned of and archived these measurements since physical examinations were required when applying for life insurance. The cumulated data showed that high BP correlated with earlier death. Now that is a perfectly reasonable actuarial basis for adjusting lifeinsurance premiums, whether or not high $\mathrm{BP}$ is actually a cause of earlier death. It is not reasonable, though, to extrapolate from that to the idea that lowering $\mathrm{BP}$ for an individual will increase that person's lifespan. Yet that extrapolation has guided medical practice for half a century. The early measurements of BP had also revealed that it rises with age. A rule of thumb half a century ago was that normal systolic BP equals age plus 100. Much data accumulated over the decades indicate that this is not far from the truth; perhaps a slight over-estimate, it may be more like 100 plus $80-90 \%$ of age (12) (Figure 1).

A very similar trend is shown in data at MedIndia (13). From the late 20s to the late 70 s, normal systolic BP rises at something like $1 \mathrm{mmHg}$ for each year of life. But the exact magnitude of the rise with age is irrelevant. The important point is just that $\mathrm{BP}$ increases normally with age. The risk of death also increases normally with age. Thus the risk of death must correlate with BP simply because both of them correlate with age. That does not suggest that lowering BP at any age is necessarily beneficial. Yet current medical practice ignores the natural increase of BP with age, and arbitrarily sets the limits of high BP or 


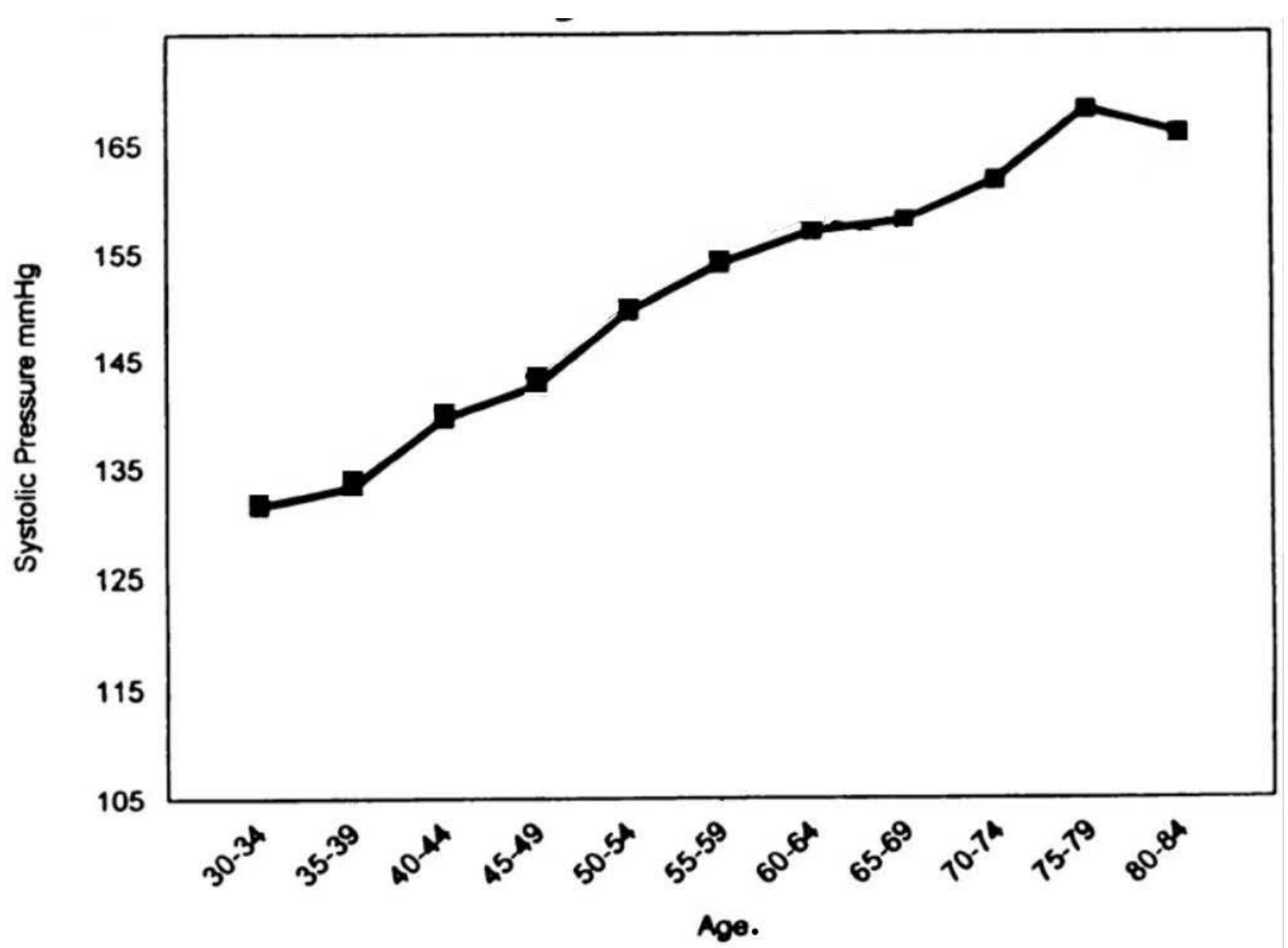

Figure 1. Normal increase in systolic blood pressure with age Overall data from the Framingham study, redrawn from Figure 1 in Franklin et al. (12).

hypertension and pre-hypertension at ageindependent numbers. For instance the National Heart, Lung \& Blood Institute defines unhealthy BP without referring to age at all (14): "The ranges in the table [Table 1 in this article] are blood pressure guides for adults who do not have any shortterm serious illnesses. People with diabetes or chronic kidney disease should keep their blood pressure below 130/80 mmHg. Although blood pressure increases seen in prehypertension are less than those used to diagnose high blood pressure, prehypertension can progress to high blood pressure and should be taken seriously".

The failure to recognize that $\mathrm{BP}$ rises normally with age becomes beyond absurd with the statement that "prehypertension can progress to high blood pressure". As presently defined, it will do so quite normally over the years. Another very serious fallacy in defining unhealthy BP in this manner is that these numbers assert that every individual should be at the population average. The same fallacy pertains to interpretation of all the other factors commonly tested: cholesterol, blood sugar, etc. In point of fact, most physiological factors vary appreciably within healthy populations. For BP, the standard deviation for apparently healthy people suggests that variations of BP by $\pm 15 \%$ or so are within the normal range (15) and should not be regarded as abnormal or unhealthy or cause for concern. Under present guidelines, a large proportion of upper-middle-aged and older people are defined as having hypertension; $75-80 \%$ of Americans aged above 60, according to the Institute of Medicine (16). Present practice is to prescribe for such "hypertension" supposedly preventive BP-lowering medications, all of them with undesirable "side" effects. This practice is misguided (17, 18). Greene (11) continues from BP with the story of how measuring numbers also led to drug-based treatments for "high" blood sugar and "high" cholesterol. The same lack 
Table 1. Defined stages of high blood pressure in adults (14).

\begin{tabular}{|l|c|c|c|}
\hline \multicolumn{1}{|c|}{ Stages } & $\begin{array}{c}\text { Systolic } \\
\text { (top number) }\end{array}$ & $\begin{array}{c}\text { Diastolic } \\
\text { (bottom number) }\end{array}$ \\
\hline Prehypertension & $120-139$ & OR & $80-89$ \\
\hline High blood pressure Stage 1 & $140-159$ & OR & $90-99$ \\
\hline High blood pressure Stage 2 & 160 or higher & OR & 100 or higher \\
\hline
\end{tabular}

of allowing for individual variability pertains here, as well as the confusion of correlation with causation.

Overall, diagnosis and treatment have become increasingly guided by numbers from tests, largely replacing individual clinical judgment based on patient's feelings and symptoms as observed and interpreted by physicians. Doctors are increasingly in groups, clinics, and large organizations, and that makes it even more difficult for individual physicians to use individual judgment, since their actions are being observed and sometimes even mandated to conform to accepted norms, namely, standard average numbers and treatments.

\section{Biomarkers, surrogate markers}

So BP, blood sugar, cholesterol and many other measures became "biomarkers" or "surrogate markers" of undesired conditions: heart disease and diabetes in these cases, later such things as bone density as a measure of the risk of bone fracture. These measures have been assumed to reflect accurately the status of the diseases themselves. The evidence is, however, that treating biomarkers has not brought the desired benefits. The surrogate markers are at best imperfect correlates of their parent disease $(16,19,20)$ and they are certainly not causes (21): "There are no valid data on the "effectiveness" of "statins [in preventing heart attacks], antihypertensives [in preventing heart attacks or strokes], and bisphosphanates [to treat osteoporosis]": because lowering cholesterol, lowering blood pressure, and increasing bone density - the surrogate markers - have never been shown respectively to result in fewer heart attacks or strokes or fewer bone fractures.

\section{Clinical trials}

The lack of reproducibility of results in medical science shows that what are reported as results of clinical trials, and the conclusions drawn from them, are not reliable. Part of the reason lies in how statistical analysis has been applied in clinical trials, discussed in a later section. But there are a whole host of other pitfalls in designing and carrying out clinical trials, and many volumes have given chapter and verse about how often these have not been avoided; in fact, protocols have too often been deliberately designed to favor a desired outcome. The three major points made and documented in these sources (22-25) and elsewhere $(1,26-28)$ are listed below.

First, trials enroll subjects not representative of those for whom a drug will later be prescribed. For example, very ill people are enrolled because beneficial effects of a drug will show up more readily. But the drugs will later be prescribed for others not nearly so ill and who may therefore not benefit. That lowering BP for someone aged 35 with readings of say 220/100 may be beneficial does not show that doing so for everyone over $140 / 90$ is beneficial. Second, safety of a drug is first tested on people who are not ill. Individuals are enrolled by offering incentives that may be very attractive to poor, homeless, or unemployed people. Enrolling in clinical trials has actually become regular employment for some people. Those who arrange these tests come to know which individuals are unusually healthy and least affected by drug "side"-effects, and they are enrolled preferentially. So the incidence of "side" effects as reported for drug approval may be considerably lower than when the drug is taken by the general public, let alone 
Table 2. Benefits and harms of statin treatment in absence of manifest heart disease.

\begin{tabular}{|l|l|}
\multicolumn{1}{|c|}{ Benefits in NNT } & Harms in NNH \\
\hline None were helped (life saved) & 1 in 50 were harmed (develop diabetes) \\
\hline 1 in 104 were helped (preventing heart attack) & 1 in 10 were harmed (muscle damage) \\
\hline 1 in 154 were helped (preventing stroke) & Harms in Percentage \\
\hline Benefits in Percentage & 2\% were harmed, developed diabetes \\
\hline 98\% saw no benefit & 10\% were harmed, muscle damage \\
\hline 0.96\% were helped, heart attack prevented & \\
\hline
\end{tabular}

Statin drugs given for 5 years for heart disease prevention (individuals without known heart disease). Data from The NNT, http://www.thennt.com/nnt/statins-for-heart-disease-prevention-without-priorheart-disease, accessed 12 August 2015.

by patients who are already ill. Third, drugs are not tested by independent investigators. Now-a-days in developed countries it is done typically by commercial Contract Research Organizations (CROs), whereas it used to be done by academic and clinical institutions with funding from drug companies. In both circumstances, the drug companies inevitably exert influence to make the results favorable to them. With academic and clinical institutions, the contracts typically contain language making the results confidential and giving the drug company control over the publication of results. The clients of CROs are the drug companies, neither the general public of prospective patients nor the members of the practicing medical profession, and a CRO gets future benefit from delivering results that please its clients.

There are many ways to bias trial protocols to get a favorable rather than an unfavorable result, and all of these are known to have been used at times: bias the choice of trial subjects and control groups; do a preliminary test and then drop from the later "actual" trial any subjects who have not benefited or who have developed bad side-effects; stop a trial at a point where the results look good even if the protocol called for a longer trial; and test a new drug against something that will ensure a favorable result (29). For instance, test a new drug against unusually high or low doses of a competing comparison drug high doses to increase "side" effects, low doses to decrease efficacy.

\section{Approving new drugs}

The flaws in clinical trials are exacerbated by regulations that are far too lax to ensure that drugs are both safe and effective. The Food and Drug Administration (FDA) requires only two successful (statistically significant) trials lasting at least 6 months. The FDA does not require results of all trials to be submitted. The results submitted for approval may have been selected from a larger number of unsuccessful trials. Six months is far too short a time to assure the safety of drugs intended to be taken lifelong, namely to treat BP, blood sugar, cholesterol, etc. The criterion for effectiveness of a drug is based on biomarkers. That does not demonstrate benefits against the actual disease. Trials are not aimed at finding the lowest useful dose of a drug, because drug companies have no interest in that; whereas patients would benefit from using the lowest beneficial dose because that decreases the 
Table 3. Statin treatment of people with heart disease.

\section{Benefits in NNT}

1 in 83 were helped (life saved)

1 in 39 were helped

(preventing non-fatal heart attack)

1 in 125 were helped (preventing stroke)

\section{Harms in NNH}

\author{
1 in 100 were harmed (develop diabetes)
}

1 in 10 were harmed (muscle damage)

Benefits in Percentage
96\% saw no benefit
1.2\% were helped, saved from death
2.6\% were helped,
repeat heart attack prevented
$0.8 \%$ were helped, stroke prevented

Statin drugs given for 5 years to individuals with known heart disease prevention. Data from The NNT; http://www.thennt.com/nnt/statins-for-heart-disease-prevention-with-known-heart-disease, accessed 29 August 2015.

chance of harmful "side" effects. Once a drug has been approved, there is no systematic monitoring of how it performs in practice. If seriously damaging "side" effects turn up, that may not come to official attention and lead to official action until an appreciable number of people have been clearly harmed, perhaps to the point of death.

The inadequacy of the present way of approving drugs is illustrated by the fact that newly approved drugs have had to be withdrawn from the market (30) after shorter and shorter times in the last few decades (6). As one result of the lack of systematic official monitoring, adverse effects often become known to consumers and lawyers before regulatory actions are taken. Drugs continue to be advertised by the manufacturers at the same time as law firms are canvassing for people to join classaction suits based on harm from the drugs' "side" effects, for instance on television in the USA in June 2015 with the anticoagulants Pradaxa and Xarelto; in September 2015 with Invokana for type 2 diabetes. That new drugs are approved when they are far from safe is also

\section{Harms in Percentage}

$1 \%$ were harmed, developed diabetes

$10 \%$ were harmed, muscle damage illustrated by the fact that prescription drugs are the $3^{\text {rd }}$ or $4^{\text {th }}$ leading cause of death in advanced countries $(24,25)$.

\section{Statistical analysis}

The almost universally used mode of statistical analysis in medical matters (and in the social sciences) assumes that the variable of interest is distributed "normally" (follows the error curve or normal or Gaussian distribution) and takes a result as "statistically significant" if $\mathrm{p} \leq 0.05$. That means less than a $5 \%$ chance, 1 in 20 that the result is not meaningful, that it came about purely by chance. In other words, treatments including drugs are being called safe and effective when that this is not the case for at least every $20^{\text {th }}$ drug; "at least" because a more rigorous technical analysis of the protocols for clinical trials suggests that the $\mathrm{p} \leq 0.05$ criterion can lead to conclusions that are wrong as much as $30 \%$ of the time (31).

But even 1 in 20 would be far too weak a criterion to satisfy the traditional form of the Hippocratic Oath, "First: do no harm". The $\mathrm{p} \leq 0.05$ criterion does not mean that there 
is only a $5 \%$ chance that an approved drug is not beneficial, it means that at least 1 in 20 of approved drugs, or as many as 3 in 10 (31), should never have reached the market in the first place, because they have no demonstrated benefit and, like all drugs, have potentially harmful "side" effects. Furthermore, that something is "statistically significant" says nothing about how large the effect is, and that matters crucially. For example, a trial of decent size $(\sim 20,000$ patients) (32) showed that clopidogrel (trade name Plavix) did better at preventing strokes and heart attacks than aspirin, at $\mathrm{p}=0.043$, well within $\mathrm{p} \leq 0.05$. But the difference in efficacy was very small: The incidence of adverse events with clopidogrel was $5.32 \%$ /year, for aspirin 5.83\%/year, a difference so small that it might not outweigh the greater risk of adverse "side" effects from clopidogrel. When a trial enrolls a large number of subjects, a statistically significant result can follow even from a tiny or negligible difference in efficacy.

Using statistical significance alone as a criterion for approving a drug makes no sense. The most informative manner of reporting the performance of drugs for the benefit of doctors and patients would be in terms of NNT (the number of patients who have to be treated to show clear benefit to one patient) and $\mathrm{NNH}$ (the number of patients who have to be treated to show clear harm to one patient). For example, to prevent one heart attack through aspirin therapy over a 2-year period, among people with no known heart disease, 2000 patients need to be treated $(\mathrm{NNT}=2000)$. But aspirin can also cause bleeding, $\mathrm{NNH}=3333$. So the chance of benefit - very small to start with - is only about twice the chance of harm (33). With statins for people with no symptoms of heart disease, the potential harm clearly outweighs the possible benefits (Table 2). On the other hand, when people already have heart disease, the benefit/risk ratio becomes less unfavorable (Table $\mathbf{3}$ ).

Still, not every patient might choose to accept an $11 \%$ chance of harm in return for a $4 \%$ chance of protection from even a serious outcome; one's family circumstances and age would be a consideration. Moreover, a Mediterranean diet by contrast to statins has been shown to lower the incidence of cardiovascular events (34). But the point here is not to advise concerning statins. It is to demonstrate that this way of presenting the data allows patients and doctors to arrive at properly informed decisions. Under present circumstances, doctors and patients are simply told by regulators and drug companies that a drug should be taken because it has been pronounced safe and effective - after inadequate testing and data analysis.

Because this illuminating NNT/NNH way of describing benefit and risk of harm is not commonly used, large numbers of people without heart disease are being prescribed statins and suffering sometimes severe "side" effects without compensating benefit; and similar conclusions probably apply to many other currently standard treatments.

\section{Big Pharma}

Most of the works listed in the cited bibliography (1) detail actions by drug companies that are against the interests of patients and thereby against the public good. Commonly mentioned are: illegally proselytizing off-label (not approved) uses of drugs approved for a different purpose, despite fines on the order of hundreds of millions, sometimes billions of dollars (35) (evidently profits from the illegal marketing are significantly larger than the fines); paying doctors and researchers to give "medical education" seminars that are actually advertisements for a drug; paying doctors and researchers to put their names on articles ghost-written by company staff; paying professional journals to publish "Supplements" of articles favoring particular drugs. Merck had even contracted with Elsevier to publish a spurious journal, Australasian Journal of Bone and Joint Medicine, that had every appearance of a normal peer-reviewed publication but that had simply been composed by Merck staff with articles favoring their drugs (36); claiming the need for high drug prices to support research when far more is spent on marketing than on research; and exerting pressure on politicians through campaign contributions and lobbying, thereby emasculating regulations and regulatory actions. 
These extraordinary charges, and more, are documented in considerable detail in a number of the books listed in my bibliography (1). Peter Gøtzsche, who directs the Nordic Cochrane Center (37), even describes Big Pharma as "Organised Crime" in the title of his book (24). Lest anyone doubt that commercial enterprises could act so much against the common good, including in ways that verge on or actually are criminal, Gøtzsche (24) and Healy (25) both compare Big Pharma to the tobacco industry, which has been shown publicly to put its profits ahead of the health of its customers. Tobacco executives knew for decades of the health dangers of smoking and that it is addictive, long before there came public campaigns against smoking. In testifying to Congressional committees, representatives of tobacco companies committed perjury. Even now-a-days Big Tobacco is marketing assiduously, going so far as to use obscure parts of trade agreements as a basis for suing governments (Australia, Britain, Uruguay and some African countries) that pass laws to make cigarette packaging unattractive $(38-40)$.

\section{Solutions}

Given that there are several causes of the present dysfunctions, no single action could fix all the problems. Practical suggestions need to take into account the present influence of Big Pharma, which has demonstrated that it will oppose strenuously anything that threatens to limit drug sales, which obviously includes tougher criteria for drug approval. Therefore initiatives for improving matters must be based on the firmest possible evidence and should include as public as possible a campaign for rational policies based on the evidence. Here the Journal of Controversies in Biomedical Research can clearly be of immediate influence. Several modifications to the process of testing and approving drugs are so clearly proper from a technical viewpoint that determined public pressure ought to be able to win out eventually: all results of all clinical trials should be made publicly available in full detail; reporting of results should include effect size, $\mathrm{NNH}$, and NNT, not merely statistical significance; and after all approvals of new drugs, there should be mandatory systematic reporting of all possible "side" effects as well as of the achieved efficacy at all doses. Various observers have estimated that at present no more than $10 \%$ of adverse events come to the attention of public agencies. As Goldacre (23), for example, has pointed out, modern electronic information technology makes it very easy for all results of drug treatment to be archived, whereupon algorithms can be used to raise flags if a particular drug appears to be associated with adverse events or with lack of efficacy.

Such actions will not be fully effective until the regulatory authorities base their decisions strictly on the evidence. That would require a wholesale elimination of conflicts of interest. Government agencies should not be in congenial arrangements with drug companies (41), and civil servants engaged in research or regulation should not be allowed to benefit from association with drug companies (42). Such elimination of conflicts of interest will be very difficult to achieve. At present, the FDA justifies its appointments to advisory panels by claiming that all the qualified individuals have some sort of research-grant or consultancy relationship with one or more drug companies. That argument is fallacious. It requires only competent statisticians to judge whether trial protocols are adequate and whether the statistical analysis of results was done properly. Allowing senior officials in the National Institutes of Health, for example, to receive payments from drug companies is clearly harmful (42) and was also rationalized by a rather feeble excuse, that the best people could not be attracted at salaries available in the Civil Service.

Even under present circumstances, it ought to be possible to strengthen the criteria by which drugs are approved in the first place. That trials need last only 6 months was put in place in the early 1990s to enable "accelerated approval" in special cases of dire need for possibly lifesaving drugs, in the context of the AIDS crisis. That procedure has become routine for all drug approvals, but it ought to be possible to restrict it to the very rare situation of something like an AIDS crisis, say for a vaccine against Ebola. Some of the current deficiencies could be greatly ameliorated if all doctors, clinics, hospitals, and health-insurance companies 
were provided with regularly updated summaries of information gleaned from the most impartial available sources, notably the Cochrane Collaboration which prepares meta-analyses and reviews of available evidence. A recent initiative is David Healy's website, Rxisk (43). After all, when law firms are able to discover quite quickly about alltoo-common and serious adverse events, it ought to be possible to provide that information at the same time - and probably even earlier - to all practicing physicians. The Internet and e-mail make such distribution eminently feasible at essentially negligible cost.

\section{Conflict of Interest}

The author declares no potential conflicts of interest with respect to research, authorship and/or publication of this article.

\section{References}

1. Bauer HH. What's wrong with present-day medicine? A periodically updated bibliography; https://dl.dropboxusercontent.com/u/5698308 1/What\%27sWrongWithMedicine.pdf, accessed 5 September 2015.

2. Claridge JA, Fabian TC. History and development of evidence-based medicine. World J Surg 2005; 9: 547-553.

http://dx.doi.org/10.1007/s00268-005-7910-1 PMid:15827845

3. Eddy DM. The origins of evidence-based medicine - A personal perspective. Virtual Mentor 2011; 13: 55-60.

http:/ /dx.doi.org/10.1001/virtualmentor.2011. 13.1.mhst1-1101

PMid:23134763

4. Zimerman AL. Evidence-Based Medicine: A short history of a modern medical movement. Virtual Mentor 2013; 15: 71-76.

http://dx.doi.org/10.1001/virtualmentor.2013. 15.1.mhst1-1301

PMid:23356811

5. List of Withdrawn Drugs; https://en.wikipedia.org/wiki/List_of_withdraw n_drugs, accessed 15 September 2015.

6. Bauer HH. Dogmatism in science and medicine: how dominant theories monopolize research and stifle the search for truth: McFarland, Jefferson (NC): 2012; 1-293 — Table 5, p. 240.
7. Anderson R. Pharmaceutical industry gets high on fat profits. 6 November 2014;

http://www.bbc.com/news/business$\underline{28212223}$, accessed 7 September 2015.

8. Big Pharma has higher profit margins than any other industry. 21 November 2014; https://www.andruswagstaff.com/blog/bigpharma-has-higher-profit-margins-than-anyother-industry, accessed 7 September 2015.

9. Corporate Watch: Pharmaceutical Industry. https://corporatewatch.org/companyprofiles/pharmaceutical-industry, accessed 7 September 2015.

10. AstraZeneca. Symbicort (for US consumers. Updated January 2015;

https://www.mysymbicort.com, accessed 14 September 2015.

11. Greene JA. Prescribing by numbers: Drugs and the definition of disease: John Hopkins University Press, Baltimore: 2007; vii-318.

12. Franklin SS, Gustin W, Wong ND, Larson MG, Weber MA, Kannel WB, Levy D. Hemodynamic patterns of age-related changes in blood pressure - The Framingham Heart Study. Circulation 1997; 96: 308-315.

http://dx.doi.org/10.1161/01.CIR.96.1.308

13. Med India. Blood pressure chart; http://www.medindia.net/patients/calculators/ bp_chart.asp, accessed 12 September 2015.

14. National Heart, Lung, and Blood Institute. Description of high blood pressure. Updated 10 September 2015; http://www.nhlbi.nih.gov/health/healthtopics/topics/hbp, accessed 12 September 2015.

15. Schwartz ML, Woloshin S. Changing disease definitions: Implications for disease prevalence Analysis of the Third National Health and Nutrition Examination Survey, 1988-1994. Eff Clin Pract 1999; 2(\#2):76-85; Figure 3.

16. Micheel CM, Ball JR (eds). for Institute of Medicine. Evaluation of biomarkers and surrogate endpoints in chronic disease: National Academies Press, Washington (DC): 2010; i-31.

17. Diao D, Wright JM, Cundiff DK, Francois Gueyffier F. Pharmacotherapy for mild hypertension. Cochrane Review, 15 August 2012, accessed 4 October 2015.

http:/ /dx.doi.org/ 10.1002/14651858.CD00674 2.pub2

18. Martin SA, Boucher M, Wright JM, Saini V. Mild hypertension in people at low risk. BMJ 2014; 349:g5432. 
http://dx.doi.org/10.1136/bmj.g5432

19. Mack A, Balogh E, Micheel C (rapporteurs) for Institute of Medicine. Perspectives on biomarker and surrogate endpoint evaluation: discussion forum summary: National Academies Press, Washington (DC): 2011; i-140.

20. Ioannidis JPA, Tzoulaki I. Minimal and null predictive effects for the most popular blood biomarkers of cardiovascular disease. Circ Res 2012; 110:658-662.

http:/ / dx.doi.org/ 10.1161/RES.0b013e31824d a8ad

21. Järvinen TL, Sievänen $H$, Kannus $P$, Jokihaara J, Khan KM. The true cost of pharmacological disease prevention. BMJ 2011; 342:1006-1008.

http://dx.doi.org/10.1136/bmj.d2175

22. Angell M. The truth about the drug companies: how they deceive us and what to do about it: Random House,

http://www.penguinrandomhouse.com: 2004; 1-319.

23. Goldacre B. Bad pharma: How drug companies mislead doctors and harm patients: Faber \& Faber (Farrar, Straus \& Giroux), New York: 2013, i-426.

24. Gøtzsche PC. Deadly medicines and organised crime: How big pharma has corrupted healthcare: Radcliffe, Oxford \& New York: 2013, i-310.

25. Healy D. Pharmageddon: University of California Press, Berkeley (CA): 2012, i-302.

26. Djulbegovic B, Hozo I, Ioannidis JPA. Improving the drug development process: More not less randomized trials. JAMA 2014; 311:355356.

http:/ / dx.doi.org/10.1001/jama.2013.283742 PMid:24449311

27. Goodman SN, Redberg RF. Opening the FDA Black Box. JAMA 2014; 311: 361-363.

http:/ /dx.doi.org/10.1001/jama.2013.283946 PMid:24449313

28. Downing NS, Aminawung JA, Shah ND, Krumholz HM, Ross JS. Clinical trial evidence supporting FDA approval of novel therapeutic agents, 2005-2012. JAMA 2014; 311:368-377. http:/ /dx.doi.org/10.1001/jama.2013.282034

29. Heres S, Davis J, Maino K, Jetzinger E, Kissling W, Leucht S. Why Olanzapine beats Risperidone, Risperidone beats Quetiapine, and Quetiapine beats Olanzapine: An exploratory analysis of head-to-head comparison studies of second-generation antipsychotics. Am J Psychiatry 2006; 163:185-194.

http://dx.doi.org/10.1176/appi.ajp.163.2.185 PMid:16449469

30. List of withdrawn drugs; http://en.wikipedia.org/wiki/List_of_withdrawn drugs, accessed 15 September 2015.

31. Colquhoun D. An investigation of the false discovery rate and the misinterpretation of $p$ values. R Soc Open Sci 2014; 1: 140216, accessed 12 September 2015.

http:/ /dx.doi.org/ 10.1098/rsos. 140216

32. Ryan, M, Combs G, Penix LP. Preventing stroke in patients with Transient Ischemic Attacks. Am Fam Physician 1999; 60:2329-2336. PMid:10593323

33. Carroll AE, Frakt A. How to measure a medical treatment's potential for harm. New York Times, 2 February 2015;

http://www.nytimes.com/2015/02/03/upshot/ how-to-measure-a-medical

treatments-potential-for-harm.html, accessed 9 September 2015

34. DuBroff $\mathrm{R}$, de Lorgeril M. Cholesterol confusion and statin controversy. World $\mathrm{J}$ Cardiol 2015; 7:404-409.

http:/ / dx.doi.org/ 10.4330/wjc.v7.i7.404

PMid:26225201 PMCid:PMC4513492

35. Wilson D. Novartis Pays $\$ 422.5$ Million in Settlement. 30 September 2010; http://www.prescriptions.blogs.nytimes.com/2 010/09/30/novartis-pays-422-5-million-insettlement accessed 12 September 2015.

36. Grant B. Merck published fake journal. 30 April 2009;

http://www.thescientist.com/?articles.view/articleNo/27376/ti tle/Merck-published-fake-journal, accessed 9 September 2015.

37. Nordic Cochrane Centre, Copenhagen; http://www.cochrane.dk/about/staff.htm, accessed 9 September 2015

38. AFTINET (Australian Fair Trade\& Investment Network Ltd). Australian High Court rules against big tobacco on plain packaging; http://aftinet.org.au/cms/node/519, accessed 7 September 2015.

39. The Independent. Big Tobacco puts countries on trial as concerns over TTIP deals mount. 16 September 2015; http://www.independent.co.uk/news/business Lanalysis-and-features/big-tobacco-puts- 
countries-on-trial-as-concerns-over-ttip-dealsmount-9807478.html, accessed 16 September 2015.

40. Jolly D. Tobacco Giants sue Britain over rules on plain packaging. 22 May 2015;

http://www.nytimes.com/2015/05/23/busines s/international/tobacco-plain-packaging-philipmorris-british-american-cigarettes.html?_r=0, accessed 15 September 2015.

41. Willman D. How a new policy led to seven deadly drugs. Los Angeles Times, 20 December 2000;

http://www.latimes.com/news/nationworld/na tion/la-122001fda,0,4840718,full.story, accessed 16 September 2015.
42. Willman D. Stealth merger: Drug companies and government medical research - Richard C. Eastman: A federal researcher who defended a client's lethal drug - John I. Gallin: A clinic chief 's desire to 'learn about industry' - Ronald N. Germain: A federal lab leader who made $\$ 1.4$ million on the side - Jeffrey M. Trent: A government accolade from a paid consultant Jeffrey Schlom: A cancer expert who aided studies using a drug wanted by a client. Los Angeles Times, 7 December 2003, pp. A1, A32-5.

43. Rxisk - Making medicines safe for all of us; http://wp.rxisk.org/about, accessed September 2015. 